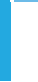

\title{
Regulation of aldosterone secretion by mineralocorticoid receptor-mediated signaling
}

\section{Cherish Chong, Anis Hamid, Tham Yao, Amanda E Garza, Luminita H Pojoga, Gail K Adler, Jose R Romero and Gordon H Williams}

Division of Endocrinology, Diabetes and Hypertension, Brigham and Women's Hospital, Boston, Massachusetts, USA
Correspondence should be addressed to G H Williams Email

gwilliams@bwh.harvard.edu

\begin{abstract}
We posit the existence of a paracrine/autocrine negative feedback loop, mediated by the mineralocorticoid receptor (MR), regulating aldosterone secretion. To assess this hypothesis, we asked whether altering MR activity in zona glomerulosa (ZG) cells affects aldosterone production. To this end, we studied ex vivo ZG cells isolated from male Wistar rats fed chow containing either high $\left(1.6 \% \mathrm{Na}^{+}(\mathrm{HS})\right)$ or low $\left(0.03 \% \mathrm{Na}^{+}\right.$ (LS)) amount of sodium. Western blot analyses demonstrated that MR was present in both the ZG and zona fasciculata/zona reticularis (ZF/ZR/ZR). In ZG cells isolated from rats on LS chow, MR activation by fludrocortisone produced a $20 \%$ and $60 \%$ reduction in aldosterone secretion basally and in response to angiotensin II (ANGII) stimulation, respectively. Corticosterone secretion was increased in these cells suggesting that aldosterone synthase activity was being reduced by fludrocortisone. In contrast, canrenoic acid, an MR antagonist, enhanced aldosterone production by up to $30 \%$ both basally and in response to ANGII. Similar responses were observed in ZG cells from rats fed HS. Modulating glucocorticoid receptor (GR) activity did not alter aldosterone production by ZG cells; however, altering GR activity did modify corticosterone production from ZF/ZR/ZR cells both basally and in response to adrenocorticotropic hormone (ACTH). Additionally, activating the MR in ZF/ZR/ZR cells strikingly reduced corticosterone secretion. In summary, these data support the hypothesis that negative ultra-short feedback loops regulate adrenal steroidogenesis. In the ZG, aldosterone secretion is regulated by the MR, but not the GR, an effect that appears to be secondary to a change in aldosterone synthase activity.
\end{abstract}

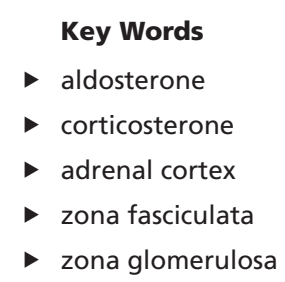

Journal of Endocrinology (2017) 232, 525-534

\section{Introduction}

Aldosterone, a major regulator of electrolyte balance and body-fluid homeostasis, is produced by the zona glomerulosa (ZG) of the adrenal cortex (Giroud et al. 1956). Aldosterone's production is regulated at early (cholesterol side chain cleavage enzyme, CYP11A1) and late (aldosterone synthase, CYP11B2) steps in its biosynthetic pathway. The renin-angiotensin system (RAS), adrenocorticotropic hormone (ACTH) and potassium are the primary modulators of aldosterone secretion (Braley \& Williams 1977, Connell \& Davies 2005). Aldosterone secretion is regulated primarily via two equally important classical negative feedback loops

Published by Bioscientifica Ltd 
focused around aldosterone's effect on the kidney: volume-RAS-aldosterone-kidney and potassiumaldosterone-kidney. Beyond its well-known renal actions, aldosterone has been shown to exert a wide range of actions in various tissues including physiologic and pathophysiological effects on the kidney, heart and vasculature (Briet \& Schriffin 2010). However, few studies have assessed the effect of steroids on steroidogenic tissues, and none have assessed the effects of mineralocorticoids.

Studies from the late 1950s suggested that glucocorticoids can modulate their own production (Birmingham \& Kurlents 1958, Peron et al. 1960, Black et al. 1961, Saito et al. 1979a, Saito et al. 1979b). However, contrasting evidence was reported. Some investigators reported an inhibition of glucocorticoid secretion when exposed to exogenous corticosteroids (Hill \& Singer 1968, Baird et al. 1983, Carsia \& Malamed 1983), whereas others reported a stimulation of glucocorticoid secretion with activation of the glucocorticoid receptor (GR) (Darbeida \& Durand 1987, Li et al. 2011, Asser et al. 2014). This discrepancy could be related to the different experimental models used as well as to the concentration and duration of the treatment. Despite uncertainties about the directional effects, these studies suggest that in addition to the traditional long feedback loops regulating steroid production, there may be a local paracrine regulatory system that affects glucocorticoids and potentially mineralocorticoids.

Similar evidence of the adrenal cortex being a potential mineralocorticoid target tissue has been more limited. Lesouhaitier and coworkers reported that aldosterone activates low-voltage calcium channels in a human adrenal carcinoma cell line (Lesouhaitier et al. 2001) similar to what we and others have reported for other ZG secretagogues (Quinn et al. 1991). Although the mineralocorticoid receptor (MR) is known to be expressed in the brain, kidney, heart and blood vessels (Pearce \& Funder 1987, Herman et al. 1989, Lombes et al. 1995), there is limited published evidence of MR protein in the adrenal cortex. However, Boulkroun and coworkers have reported immunohistological evidence for MR in human adrenals and aldosteronomas (Boulkroun et al. 2010).

Given the lack of data coupled with supporting evidence from previous studies of a glucocorticoid paracrine effect but with the suggestive evidence for the presence of a MR in the ZG, we proposed that an ultrashort feedback loop regulating aldosterone secretion would be present in ZG cells. In this study, we explore the extent of MR and GR involvement in the regulation of adrenocortical steroid production. To address this aim, we first determined the expression of MR in the adrenal cortex. The activity of the MR in isolated ZG cells was then pharmacologically modulated with either fludrocortisone, a MR agonist, or canrenoic acid, a MR antagonist. Finally, we assessed the specificity of the feedback loop by modifying GR activity in these cells and modifying both GR and MR activity in ZF/ZR cells.

\section{Materials and methods}

\section{Experimental animals}

All studies were conducted in accordance and approval from the Harvard Medical Area Standing Committee on Animals and institutional guidelines for the humane treatment of animals. Male Wistar rats weighing between 175 and $200 \mathrm{~g}$ were obtained from Charles River Laboratories, Inc.. All animals were housed in a room lighted $12 \mathrm{~h}$ /day at an ambient temperature of $22 \pm 8^{\circ} \mathrm{C}$. Animals were started on either low-sodium (LS) rat chow containing $0.03 \% \mathrm{Na}^{+}$or high/liberal sodium (HS) rat chow containing $1.6 \% \mathrm{Na}^{+}$(Purina, St. Louis, MO, USA) and had free access to tap water for 5-7 days before killing.

\section{Separation of zona glomerulosa and zona fasciculata}

Isolation of ZG and ZF/ZR/ZR cells was performed as previously reported by us (Braley \& Williams 1977, Quinn et al. 1991). In brief, rats were anesthetized with isoflurane, and their adrenals were excised rapidly and placed in ice-cold Krebs-Ringer bicarbonate (KRBGA) solution $(0.1 \%$ BSA, $200 \mathrm{mg}$ glucose/dL, L-glutamine, $3.7 \mathrm{mmol} / \mathrm{L}$ of $\left.\mathrm{K}^{+}\right)$. The adrenals were freed from adhering fat and loose connective tissue, bisected and separated into a capsulated portion containing predominantly ZG and decapsulated portion containing the ZF/ZR and adrenal medulla. The adrenal medulla was carefully dissected free from the ZF/ZR. Tissues were then combined with collagenase $(3.7 \mathrm{mg} / \mathrm{mL})$ and DNAase $(0.05 \mathrm{mg} /$ $\mathrm{mL}$ ) (Worthington Biochemical, Free-hold, NT, USA) in KRBGA solution and incubated for $60 \mathrm{~min}$ in a Dubnoff metabolic shaker at $37^{\circ} \mathrm{C}$ under $95 \% \mathrm{O}_{2}$ and $5 \% \mathrm{CO}_{2}$. The cell suspension was mechanically disrupted with a pipette and was filtered. Cells were then centrifuged at $152 \boldsymbol{g}$ at $25^{\circ} \mathrm{C}$ and washed three times with the supernatants discarded and then re-suspended in KRBGA solution. Cells were re-incubated for $30 \mathrm{~min}$ and washed twice later, and cell count and purity were assessed microscopically. ZG cells were smaller than ZF/ZR cells, and ZF/ZR cells

Published by Bioscientifica Ltd. 
contained lipid droplets that were largely absent from ZG cells. Microscopically, the ZG prep contained $<5 \%$ ZF/ZR cells. All experiments were carried out in duplicates, and cells $\left(6 \times 10^{4}\right)$ were incubated at $37^{\circ} \mathrm{C}$ under $95 \% \mathrm{O}_{2}$ and $5 \% \mathrm{CO}_{2}$.

\section{Pharmacological treatments}

Cells were treated with various concentrations of fludrocortisone acetate (FLUDRO, Sigma-Aldrich), canrenoic acid (Sigma-Aldrich), dexamethasone (DEX, Sigma-Aldrich) or RU486 (Sigma-Aldrich) in the presence or absence of angiotensin II (ANGII, Sigma-Aldrich) or ACTH (cosyntropin, Amphastar Pharmaceutical Inc., Rancho Cucamonga, CA, USA). FLUDRO, DEX and RU486 were added to the cells $15 \mathrm{~min}$ prior to the addition of ANGII or ACTH for another hour in all experiments.

\section{Western blot analysis}

Adrenal tissues were homogenized in ice cold lysing solution containing radioimmunoprecipitation assay (RIPA) buffer (Boston Bioproducts, Worchester, MA, USA) and protease inhibitor cocktail (Pierce Biotechnology). Homogenates were then centrifuged at $24,400 \boldsymbol{g}$ for $15 \mathrm{~min}$ at $4^{\circ} \mathrm{C}$. Supernatants were transferred to a microcentrifuge tube without disturbing the pellets. Protein concentration was determined using the Pierce BCA protein assay kit (Pierce Biotechnology). Supernatants $(50 \mu \mathrm{g}$ of protein) were combined with $6 \times$ Laemmli SDS-Sample buffer (Boston Bioproducts), heated at $95^{\circ} \mathrm{C}$ for $5 \mathrm{~min}$ and size-fractionated by electrophoresis on $10 \%$ SDSpolyacrylamide gels. Proteins were electrophoretically transferred to Protran Nitrocellulose Membranes (Perkin Elmer). Membranes were blocked in 5\% non-fat dried milk in Tris-buffered saline (TBST) (Boston Bioproducts) for $1 \mathrm{~h}$ at room temperature on an orbital shaker. Incubation with primary antibody was done overnight at $4^{\circ} \mathrm{C}$ with antibody diluent consisting of $1 \%$ non-fat dried milk in TBST. Primary antibodies were mouse anti-CYP11B1 (Cat \#sc-377248, Santa Cruz Biotechnology, Inc., dilution 1:200), mouse anti-CYP11B2 (Cat \#MAB6021, Millipore, dilution 1:200), rabbit anti-GR (Cat \#sc-8992, Santa Cruz Biotechnology, Inc., dilution 1:500) and rabbit anti-MR (Cat \#sc-11412, Santa Cruz Biotechnology, Inc., dilution 1:2000). The bound antibody is detected by enhanced chemiluminescence (ECL) (HyGLO Quick Spray Chemiluminescent, Denville Scientific, South Plainfield, NJ, USA) with HRP-conjugated goat anti-mouse IgG
(Cat \#sc-2031, Santa Cruz Biotechnology, Inc., dilution 1:6000) or goat anti-rabbit IgG (Cat \#sc-2004, Santa Cruz Biotechnology, Inc., dilution 1:10,000). All Western blots were re-probed with anti- $\beta$-tubulin antibody, and the protein of interest was normalized to $\beta$-tubulin to correct for loading variability. Data are presented as fold change relative to the measurement in rats on a low-sodium diet.

\section{Assays and analyses}

Serum aldosterone and aldosterone levels in incubates were measured by Aldosterone Radioimmunoassay (RIA) kit (IBL International, Hamburg, Germany). Corticosterone was quantified with ImmuChem Corticosterone Double Antibody RIA kit (MP Biomedicals, Orangeburg, NY, USA).

\section{Statistical analysis}

Data are expressed as mean \pm s.E.M. Paired data were compared by Student's $t$ tests. Comparisons between multiple groups were made with two-way ANOVA followed by Dunnett's post hoc test for multiple comparisons. Data were analyzed using GraphPad Prism 6 software. Differences with $P$ values $<0.05$ were considered statistically significant.

\section{Results}

\section{Effect of dietary sodium on aldosterone and corticosterone}

Serum aldosterone levels and basal production of aldosterone in isolated ZG cells were significantly lower in rats on a HS diet as compared to a LS diet (Table 1). In contrast, serum corticosterone levels and basal production of corticosterone in isolated ZF/ZR cells were significantly increased in rats on a HS versus LS diet (Table 1). Dietary sodium did not affect corticosterone production by ZG cells.

\section{Expression of MR and GR in the adrenal cortex}

MR and GR were highly expressed in both rat ZG and ZF/ZR cells. No changes in MR and GR protein expression were observed in the $Z G$ with changes in sodium intake (Fig. 1). However, in the ZF/ZR, GR levels were increased on a HS diet suggesting an enhanced capability for glucocorticoid signaling (Fig. 2). To assess for contamination between the ZG and ZF/ZR preparations,

Published by Bioscientifica Ltd. 
Table 1 Effect of sodium diets on serum levels and ex vivo baseline and stimulated levels of aldosterone and corticosterone by ZG and ZF/ZR cells. The number of replicates is shown in ().

\begin{tabular}{|c|c|c|}
\hline & Low salt $\left(0.03 \% \mathrm{Na}^{+}\right)$ & High salt $\left(1.6 \% \mathrm{Na}^{+}\right)$ \\
\hline \multicolumn{3}{|l|}{ Serum levels } \\
\hline Aldosterone (ng/dL) & $31.01 \pm 4.33(5)$ & $5.45 \pm 0.82(5)^{a}$ \\
\hline Corticosterone ( $\mu \mathrm{g} / \mathrm{dL})$ & $6.11 \pm 2.02(5)$ & $21.89 \pm 7.30(5)^{b}$ \\
\hline \multicolumn{3}{|l|}{ Zona glomerulosa } \\
\hline \multicolumn{3}{|l|}{ Baseline } \\
\hline Aldosterone (ng/h/106 cells) & $56.87 \pm 6.29(42)$ & $1.46 \pm 0.13(8)^{a}$ \\
\hline Corticosterone (ng/h/106 cells) & $1536.00 \pm 201.30(11)$ & $1468.00 \pm 149.30(8)$ \\
\hline \multicolumn{3}{|l|}{ Response to Angll } \\
\hline Aldosterone (ng/h/106 cells) & $118.3 \pm 11.17(32)$ & $21.36 \pm 7.01(10)^{a}$ \\
\hline Corticosterone (ng/h/106 cells) & $1998.0 \pm 188.6(13)$ & $3175.0 \pm 550.6(8)^{b}$ \\
\hline \multicolumn{3}{|l|}{ Zona fasciculata/reticularis } \\
\hline \multicolumn{3}{|l|}{ Baseline } \\
\hline Corticosterone (ng/h/106 cells) & $1023.00 \pm 77.77(28)$ & $1820.00 \pm 191.00(6)$ \\
\hline \multicolumn{3}{|l|}{ Response to ACTH } \\
\hline Corticosterone (ng/h/106 cells) & $8355.00 \pm 1099.00(28)$ & $9252.00 \pm 1423.00(6)$ \\
\hline
\end{tabular}

Data show average \pm S.E.M.

${ }^{a} P<0.0005$ for high salt vs low salt. ${ }^{b} P<0.05$ for high salt vs low salt.

we analyzed aldosterone synthase (CYP11B2) and 11 $\beta$-hydroxylase (CYP11B1) expressions in these cells. CYP11B2 is expressed only in the ZG cells, whereas CYP11B1 is expressed mainly in the ZF/ZR cells. CYP11B2
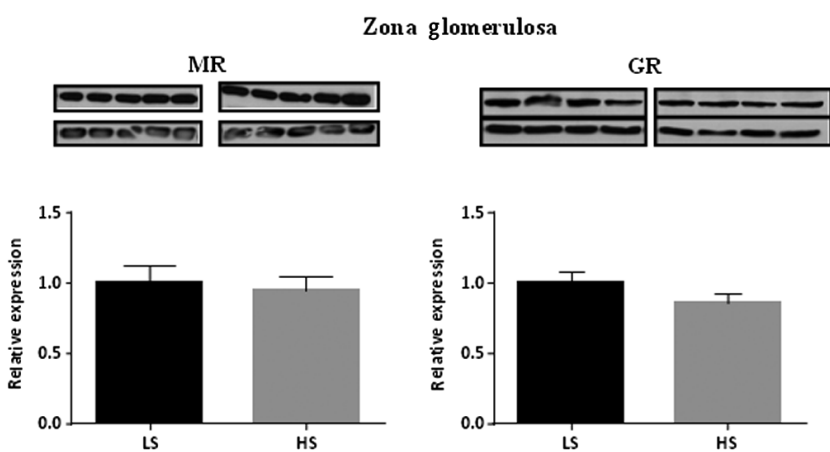

CYP11B2
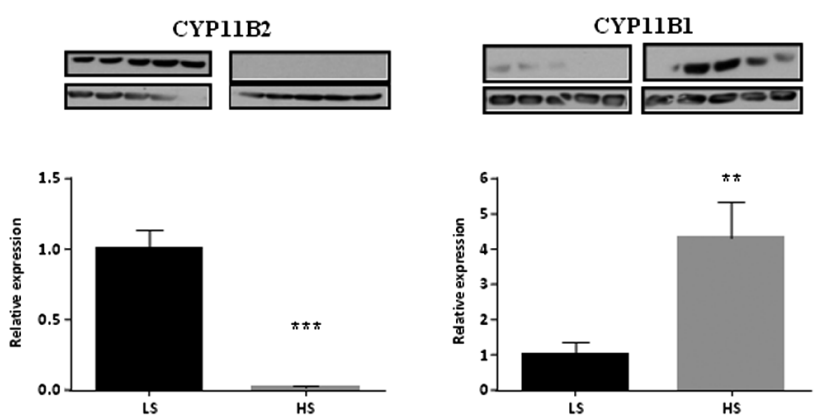

Figure 1

Western blot analyses showing expression of MR, GR, CYP11B2 and CYP11B1 in zona glomerulosa cells obtained from rats maintained on low-salt (LS) or high-salt (HS) diets. HS diet reduced CYP11B2 levels but increased CYP11B1 expression. Representative Western blots are shown above each graph. $n=9$ per group (Controls are the lower panels). $* * P<0.01 ; * * * P<0.001$ levels in the ZG were reduced under HS conditions as would be expected from suppression of aldosterone secretion. Interestingly, HS diet was associated with an increase in CYP11B1 in ZG cells, whereas there were no
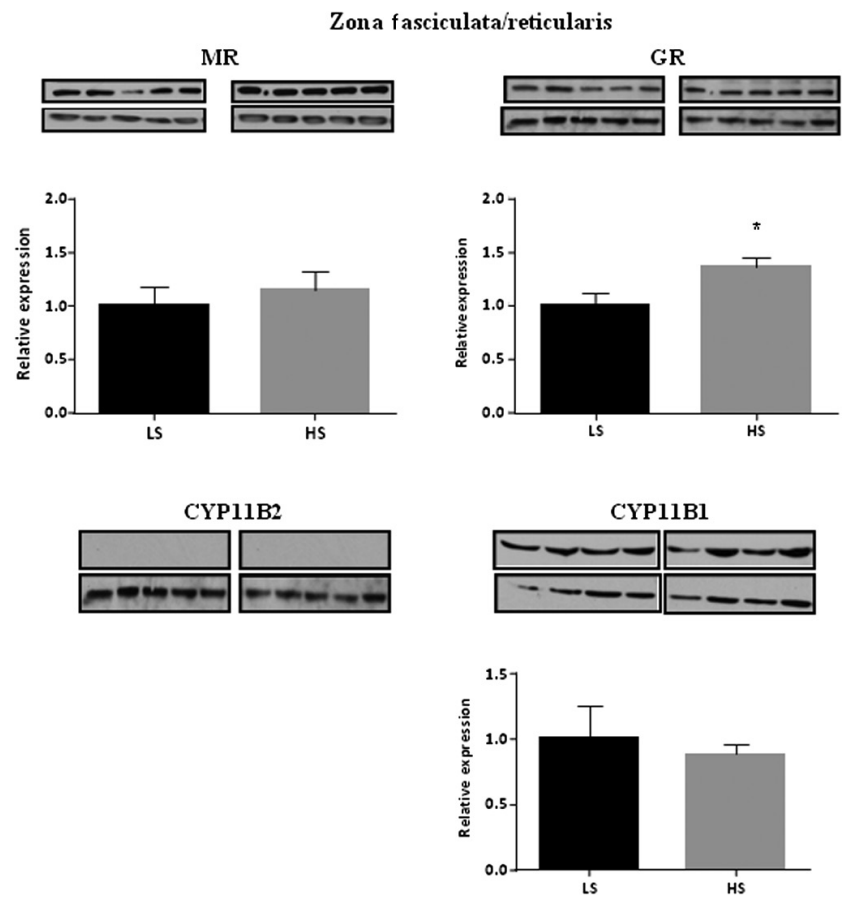

Figure 2

Western blot analyses showing the expression of MR, GR, CYP11B2 and CYP11B1 in zona fasciculata/reticularis cells obtained from rats maintained on low-salt (LS) or high-salt (HS) diets. CYP11B1 levels are not significantly affected by dietary salt. CYP11B2 was non-detectable in these cells. Representative Western blots are shown above each graph (Controls are the lower panels). $n=9$ per group. ${ }^{\star} P<0.05$.

Published by Bioscientifica Ltd http://joe.endocrinology-journals.org DOI: $10.1530 / J O E-16-0452$ (c) 2017 Society for Endocrinology Printed in Great Britain 
changes in ZF/ZR CYP11B1 when dietary sodium intake was changed. We did not detect any CYP11B2 in the ZF/ZR suggesting that we have minimal, if any, contamination of the ZF/ZR with ZG cells (Fig. 2). Microscopically, there was $<5 \%$ contamination of ZF/ZR cells in the ZG prep.

\section{Effect of MR modulation on aldosterone secretion in ZG cells obtained from sodium-restricted rats}

We modulated MR functionality in isolated ZG cells using FLUDRO, a MR agonist, and canrenoic acid, a MR antagonist, in the presence or absence of ANGII stimulation. Pretreatment with FLUDRO suppresses aldosterone production under both basal and stimulated conditions (Fig. 3). In the ANGII-stimulated cells, $40 \mu \mathrm{M}$ FLUDRO reduced aldosterone secretion by $60 \%$ as compared to the control ANGII-stimulated condition $(P<0.001)$. Under basal conditions, $40 \mu \mathrm{M}$ FLUDRO reduces aldosterone secretion by $25 \% \quad(P<0.05)$. In contrast, MR blockade with canrenoic acid resulted in a dose-dependent increase in aldosterone levels (Fig. 4). Exposure to increasing concentrations of canrenoic acid significantly enhanced aldosterone production by $10-30 \%$ in the basal and ANGII-stimulated groups.

\section{Site of regulation of aldosterone biosynthesis}

To determine the potential site at which the MR regulates aldosterone biosynthesis, we measured corticosterone secretion from ZG incubates from low salt rats. Corticosterone is converted by CYP11B2 to aldosterone. Although FLUDRO treatment reduced aldosterone secretion, it increased corticosterone (Fig. 5A and B), suggesting that MR activation inhibits the activity of the late pathway, specifically aldosterone synthase
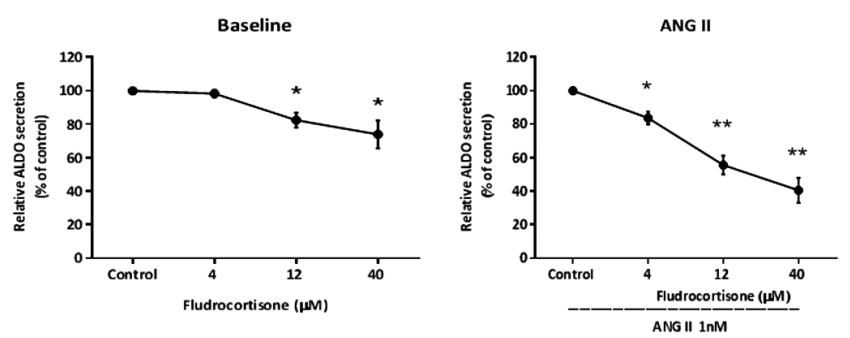

Figure 3

Effect of activation of MR by fludrocortisone (FLUDRO) on basal (left panel) and stimulated (right panel) aldosterone release by zona glomerulosa cells from low salt-treated rats. Results are means \pm S.E.M. $(n=8)$ and are expressed as percentage of secretion with controls set at $100 \%$. ${ }^{\star} P<0.05, * * P<0.001$.
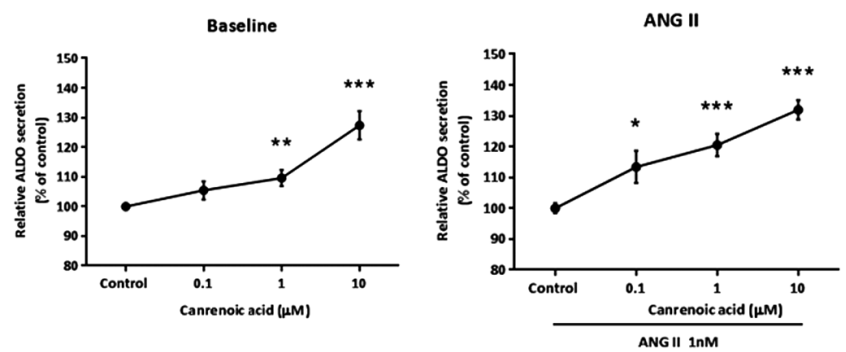

Figure 4

Effect of MR inhibition on baseline and ANGII-stimulated aldosterone secretion by isolated zona glomerulosa cells from rats fed a low-salt diet. Results are means \pm S.E.M. $(n=22)$ and are expressed as percentage of secretion with controls set at $100 \%$. ${ }^{*} P<0.05,{ }^{* *} P<0.01,{ }^{* * *} P<0.0001$.

(CYP11B2). Blocking the MR with canrenoic acid did not affect corticosterone secretion (Fig. 5C and D).

\section{Effect of dietary sodium on aldosterone steroidogenesis}

We next examined whether the MR would regulate aldosterone production in ZG cells from rats fed an HS diet. FLUDRO significantly inhibited ANGII-stimulated aldosterone secretion (Fig. 6B), as was observed in ZG cells obtained from rats fed an LS diet. However, in ZG cells obtained from rats fed a HS diet, FLUDRO did not alter basal aldosterone secretion (Fig. 6A), and canrenoic acid treatment did not alter basal or ANGII-stimulated aldosterone production (Fig. 6C and D).
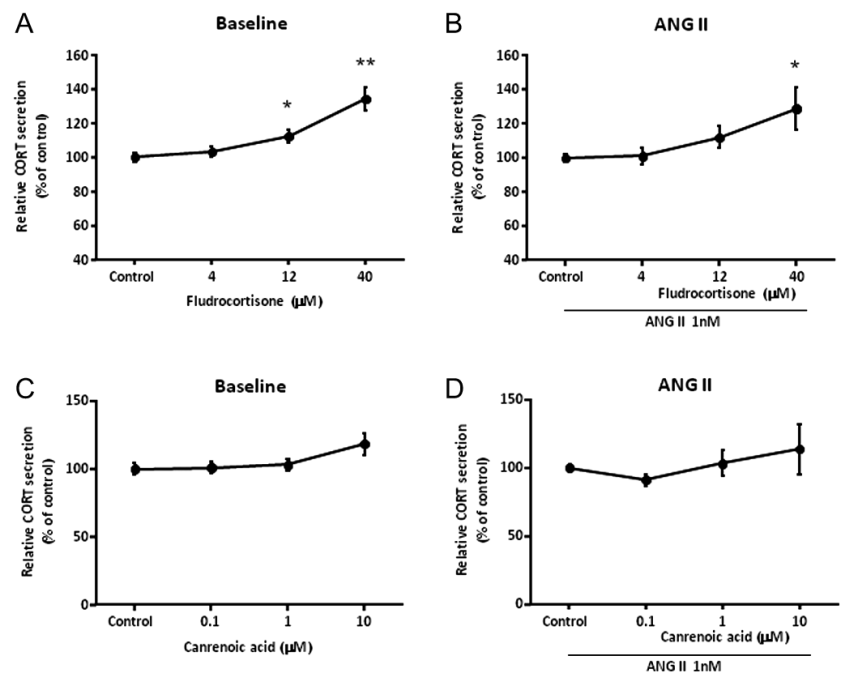

Figure 5

Corticosterone (CORT) secretion in isolated zona glomerulosa cells from rats on a low-salt diet with FLUDRO $(A, B$ with $n=8)$ and canrenoic acid (C, D with $n=22$ ) treatment. Results are means \pm S.E.M. and are expressed as percentage of secretion with controls set at $100 \%$. ${ }^{*}<0.05$, $* * P<0.005$

Published by Bioscientifica Ltd. 
A
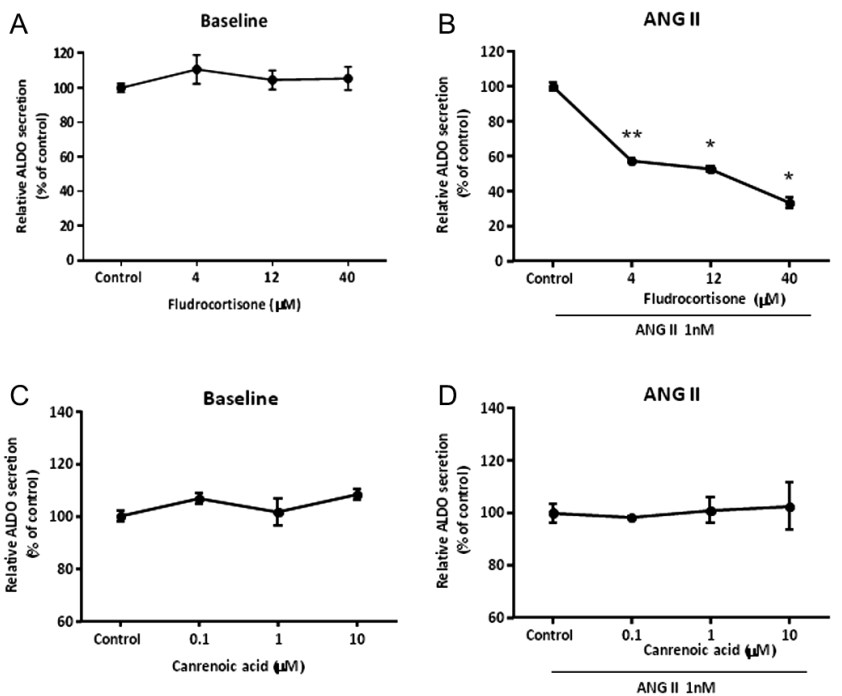

Figure 6

Modulation of MR function in zona glomerulosa cells from rats on a high-salt diet. Effect of FLUDRO (A, B with $n=4)$ and CAN (C, D with $n=6$ ) on aldosterone secretion. Results are means \pm S.E.M. and are expressed as percentage of secretion with controls set at $100 \%$. ${ }^{*} P<0.005, * * P<0.001$.

\section{Effect of DEX and RU486 on aldosterone production in ZG cells}

To determine the specificity of these findings, we investigated the effect of stimulating and inhibiting the GR on aldosterone output from ZG cells from rats fed a low-salt diet. To accomplish this, we treated the ZG cells with DEX, a GR agonist, and RU486, a GR antagonist. Neither DEX nor RU486 treatment significantly affected basal or ANGII-stimulated aldosterone production (Fig. 7). Together, these results suggest that aldosterone secretion in rat ZG cells can be regulated within the adrenal tissue exclusively by the MR, consistent with an ultra-short feedback loop with aldosterone regulating its own production.

\section{Effect of GR activity on corticosterone in ZF/ZR cells}

We also investigated the effect of DEX and RU486 on corticosterone production in ZF/ZR cells from rats on a LS diet. DEX reduced ACTH-stimulated production of corticosterone by up to $70 \%$ at $10 \mu \mathrm{M}(P<0.0001)$. Corticosterone secretion in baseline conditions was not altered (Fig. 8). Increasing concentrations of RU486 significantly stimulated corticosterone levels by 2.5 -fold. No changes in basal corticosterone concentrations were observed when exposed to RU486 (Fig. 9). Our results are consistent with the findings of prior studies demonstrating the regulation of
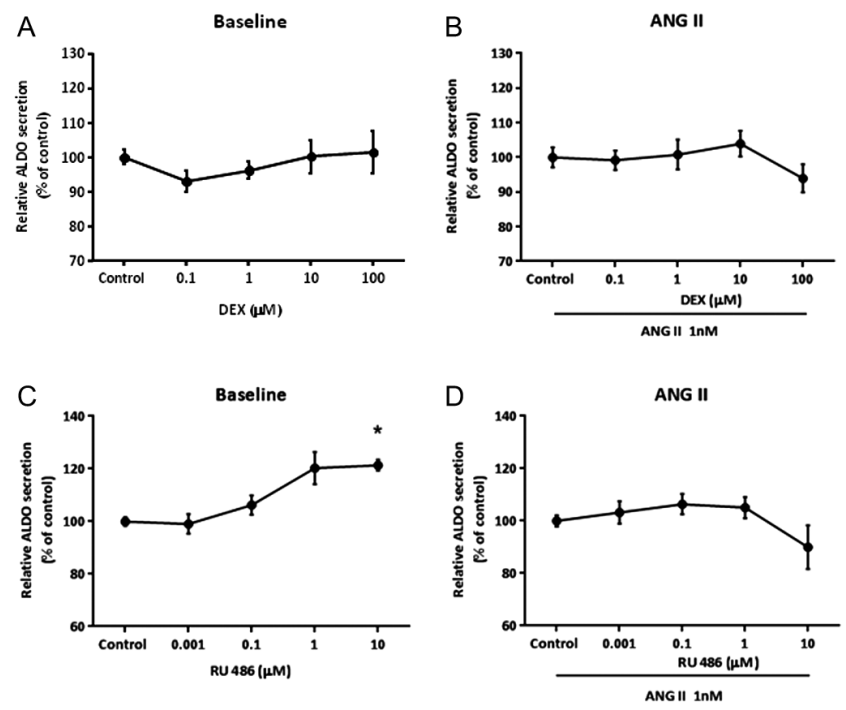

Figure 7

Effect of modifying GR activity on aldosterone secretion in zona glomerulosa cells from low salt fed rats. Cells were incubated with DEX. a GR agonist (A, B) and RU486, a GR antagonist (C, D). Results are means \pm S.E.M. with $n=6$ and are expressed as percentage of secretion with controls set at $100 \%$. ${ }^{*} P<0.005$.

glucocorticoid production by modulating GR activity in the adrenal cortex.

\section{Effect of MR modulation on glucocorticoid feedback in ZF/ZR cells}

Seeing that aldosterone regulation in the $\mathrm{ZG}$ is mediated by $\mathrm{MR}$ and not GR, we then proceeded to determine whether we would observe the same specificity in the $\mathrm{ZF} / \mathrm{ZR}$ for glucocorticoid regulation. Unexpectedly, activation of MR in the ZF/ZR inhibited corticosterone secretion in cells obtained from both LS and HS fed rats (Fig. 10). However, MR blockade did not have any significant effect on corticosterone production in the ZF/ZR (Fig. 11). Therefore, it appears that both the MR
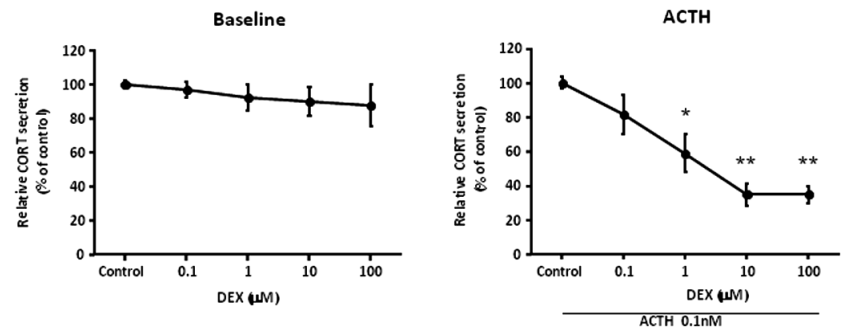

\section{Figure 8}

Inhibition of stimulated corticosterone secretion by DEX in zona fasciculata/reticularis cells from low salt fed rats. Results are means \pm S.E.M. $(n=8)$ and are expressed as percentage of secretion with controls set at $100 \%$. ${ }^{*} P<0.05, * * P<0.0005$.

Published by Bioscientifica Ltd. 

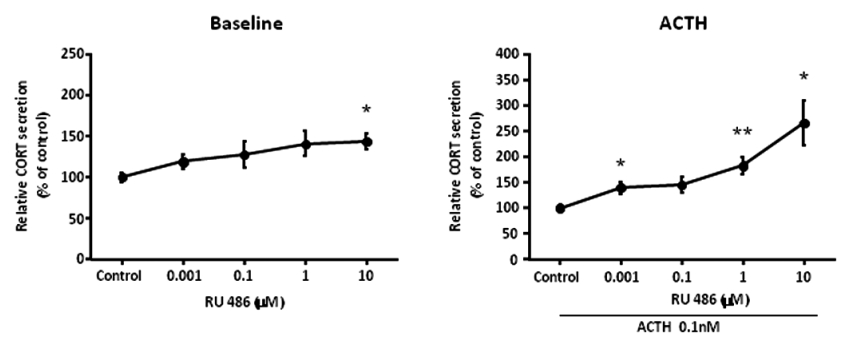

Figure 9

RU486 treatment stimulates corticosterone production in ACTH-stimulated zona fasciculata/reticularis cells from rats fed a low-salt diet. Results show means \pm S.E.M. $(n=8)$ and are expressed as percentage of secretion with controls set at $100 \%$. ${ }^{*} P<0.05, * * P<0.005$.

and GR can regulate glucocorticoid production in ZF/ZR cells.

\section{Discussion}

In the present study, we demonstrated that MR and GR are present in the rat adrenal cortex. We showed that altering MR activity regulates aldosterone production in the ZG in a manner that fits a negative feedback mechanism. This effect is specific for the MR, as modulating the activity of the GR in the ZG had no effect on aldosterone production. To our knowledge, this is the first time that MR expression and its role in regulating aldosterone secretion within the adrenal cortex have been reported. In the ZF/ZR, we observed a similar feedback
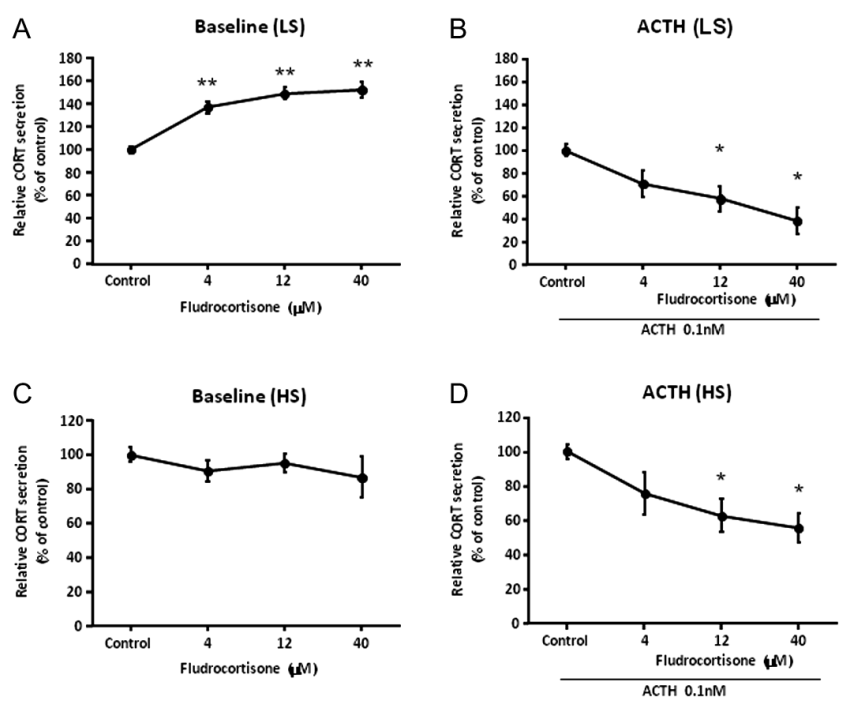

Figure 10

Effect of MR activation on corticosterone from low salt (LS, top panels) and high salt (HS, bottom panels) zona fasciculata/reticularis cells. Results are means \pm S.E.M. $(n=6)$ and are expressed as percentage of secretion with controls set at $100 \%$. ${ }^{*} P<0.05, * * P<0.005$.
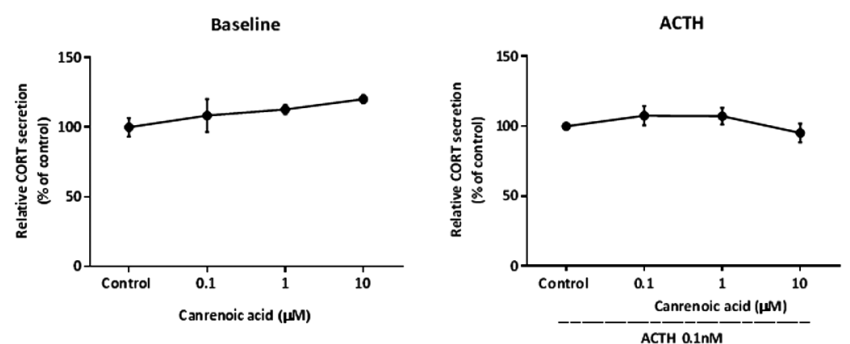

Figure 11

MR blockade with canrenoate did not alter corticosterone secretion in basal and ACTH-stimulated zona fasciculata/reticularis cells on low salt. Results are means \pm S.E.M. $(n=6)$ and are expressed as percentage of secretion with controls set at $100 \%$.

loop when we pharmacologically modified the activity of the GR. Interestingly, MR activation also suppressed corticosterone secretion in ZF/ZR cells. Our findings are in agreement with previous studies showing that adrenal glucocorticoid synthesis can be modulated by steroids synthesized within the adrenal cortex (Baird et al. 1983, Carsia \& Malamed 1983, Darbeida \& Durand 1987).

MR activation with FLUDRO exerted a negative effect on aldosterone production in ZG cells prepared from rats maintained on both HS and LS diets, whereas canrenoic acid, an MR antagonist, positively regulated steroidogenesis with an increase in aldosterone secretion in ZG cells from LS fed rats. We saw a more pronounced response in the LS groups as compared to that in the HS groups. The lack of effect of a GR agonist and antagonist on basal and stimulated aldosterone release from the ZG cells is highly indicative that the regulatory feedback loop is receptor specific.

What might be the physiologic and clinical relevance of an aldosterone ultra-short feedback loop? There is a tight relationship between aldosterone production and environmental factors, e.g., sodium and potassium intakes, posture, time of day and volume loss. It has long been established that inappropriate levels of aldosterone, for the level of these environmental factors, leads to a variety of cardiovascular and metabolic diseases in humans and other animals. Therefore, critically sensitive negative feedback loops are important for the maintenance of normal homeostasis. This is particularly relevant for volume/sodium homeostasis as even minor misalignment of responses to changes in environmental sodium intake over time can lead to substantial adverse cardiovascular effects. These potential consequences are likely why there are several checks and balances in the systems regulating volume/sodium homeostasis, e.g., renin-angiotensin system, aldosterone, natriuretic peptides, endothelin, vasopressin and the kidney (renal

Published by Bioscientifica Ltd 
blood flow, proximal tubule, loop of Henle and distal tubule/collecting duct). These regulatory factors are controlled, in part, by: (1) 'long' negative feedback loops, e.g., volume-renin-angiotensin-aldosterone negative feedback loop; (2) direction of action of opposing acting factors, e.g., natriuretic peptides suppressing aldosterone secretion and (3) ultra-short feedback loops, e.g., direct suppression of renin release from the juxtaglomerular apparatus by angiotensin II's interaction with the angiotensin receptor-type 1 . In some respects, ultrashort feedback loops' functions are analogous to the near universal concept of product inhibition of enzyme function. Parallel to angiotensin II's effect, the current study supports the hypothesis that there is also an ultrashort feedback loop that modifies aldosterone production at its point of final synthesis using the level of aldosterone and the MR. This step further refines the production of aldosterone to ensure that it is appropriate for the environment in which the organism currently resides. Of course, it also provides another point in these volume homeostatic mechanisms where dysfunction can lead to cardiovascular dysfunction and disease. Two reports are potentially relevant to these possibilities. In contrast to the present studies in normal ZG cells where RU 486 had no effect on aldosterone secretion, in two altered conditions, primary aldosterone tumor cells (Burton et al. 2011) and Zucker obese hypertensive rats (Clapham \& Turner 1997), RU 486 suppressed plasma aldosterone but not plasma corticosterone levels. Similar to the present study, RU 486 did not alter aldosterone levels in the control rats (Clapham \& Turner 1997). Of interest, in the tumor cells, MR antagonists had no effect on aldosterone production. Activation of the MR was not performed. Because similar levels of aldosterone and cortisol were found in the cell preparations, cellular admixture was present or an altered cell type was present (Burton et al. 2011). Finally, the results of the present study may be applicable to the regulation of steroids outside the adrenal with their likely physiologic and clinical relevance.

How do changes in MR activity modify aldosterone secretion? The increase in corticosterone secretion with a concomitant suppression in aldosterone production suggests that the late pathway of aldosterone biosynthesis is the site of regulation. The last step in the synthesis of aldosterone relies on the activity of CYP11B2 (aldosterone synthase) (Mornet et al. 1989). The decrease in conversion of corticosterone to aldosterone is most likely due to decreased activity of CYP11B2 and not to a change in CYP11B2 expression because of the short $(1 \mathrm{~h})$ duration of our experiments. Our finding of decreased CYP11B2 protein levels under HS conditions and the proposed mechanism of modification of CYP11B2 activity by MR likely accounts for the attenuation of the regulatory feedback loop on a high-salt diet.

Low sodium intake is a well-known stimulator of aldosterone secretion (Marusic \& Mulrow 1967, Aguilera $\&$ Catt 1979), and our results are in line with these reports. We observed an elevation in serum corticosterone with a high-salt diet. Consistent with an increase in serum corticosterone, isolated ZF/ZR cells from rats on a high salt diet showed higher basal corticosterone secretion. The mechanisms by which dietary sodium affects corticosterone secretion have not been investigated although previous studies have shown that adrenals of sodium-deficient rats have reduced secretion of corticosterone (Eisenstein \& Strack 1961). Corticosterone can be produced by both the ZF/ZR and the ZG, though most of the circulating corticosterone comes from the ZF/ZR because of their substantially greater mass. However, as basal corticosterone release from ZG cells was not affected by changes in dietary sodium intake, we deduced that the ZF/ZR cells contributed to the rise in serum corticosterone with high sodium intake.

The existence of an intra-adrenal feedback loop exerted by glucocorticoids and GR to regulate glucocorticoid production has long been suggested by several in vivo (Peron et al. 1960, Hill \& Singer 1968) and in vitro studies (Morrow et al. 1967, Carsia \& Malamed 1983). These studies report contrasting results as to whether glucocorticoids inhibit or stimulate glucocorticoid production. The direction of regulation seems to depend on the experimental model used and the duration of treatment. In this study, we provide evidence of a negative regulatory feedback on corticosterone secretion consistent with the findings of Carsia \& Malamed (1983), although other investigators have reported opposite findings (Darbeida \& Durand 1987, Li et al. 2011, Asser et al. 2014). Despite the large body of work, the mechanisms by which glucocorticoids regulate steroidogenesis are not well understood. Our results showing a marked depression in corticosterone secretion only in ACTH-stimulated ZF/ ZR cells with DEX treatment are in accordance with the findings of Latner and coworkers (Latner et al. 1977), which suggest that glucocorticoids decrease the binding of ACTH to its receptor. In addition, the glucocorticoid antagonist, RU 486 did not affect basal corticosterone secretion but stimulated corticosterone production by ACTH. These data point to the possibility that GR activity modifies the sensitivity of ZF/ZR cells to ACTH. Other work using longer incubation times suggest that

Published by Bioscientifica Ltd 
glucocorticoids inhibit protein synthesis and regulate transcription on several target genes in the adrenal cortex (Morrow et al. 1967, Asser et al. 2014). Though this explanation seems unlikely in our study because of the duration of our experiments, we cannot exclude the possibility that genomic effects might have contributed to our observations.

A surprising finding in our study was that the $\mathrm{ZF} / \mathrm{ZR}$ in contrast to the $\mathrm{ZG}$ does not demonstrate receptor specificity. Activating the GR or the MR can suppress corticosterone production in the ZF/ZR. MR activation has been reported to modulate glucocorticoid production, but this effect is demonstrated only in the brain. Administration of fludrocortisone in humans was found to inhibit cortisol concentrations by downregulation of the hypothalamic-pituitary axis (HPA) (Otte et al. 2003, Buckley et al. 2007, Lembke et al. 2013). The clear influence of MR in glucocorticoid HPA feedback control was further demonstrated when canrenoic acid was shown to have an opposite effect on cortisol and ACTH secretion (Arvat et al. 2001, Wellhoener et al. 2004). Our findings suggest that in addition to MR activity centrally regulating glucocorticoid production, it also can regulate it locally in the adrenal, although the regulation apparently depends on the level of salt intake. On both diets in response to ACTH, MR activation inhibits corticosterone production, but, for unclear reasons, on the low salt diet it appears to increase corticosterone levels. Given that in vivo the adrenal blood flow is from ZG to the ZF/ZR, aldosterone could have paracrine effect on glucocorticoid production with interesting physiologic and pathophysiologic implications.

One limitation of the study was that contamination between the glomerulosa and fasciculata zones could potentially obscure changes in response to different stimuli. We think this is unlikely based on the absence of CYP11B2 in the ZF/ZR and microscopic data, where the $\mathrm{ZF} / \mathrm{ZR}$ and $\mathrm{ZG}$ cells have distinctly different characteristics, showed little if any contamination in the two cell preps. A second limitation is that the present study cannot assess the relative importance of these paracrine vs the classical endocrine effects controlling adrenal steroidogenesis. A third limitation is that we do not know if cortisol or corticosterone by interacting with the MR may have the same effect as aldosterone. However, as mentioned previously, given the direction of blood flow from glomerulosa to fasciculata zones, if it occurred it would not be a local, paracrine effect. Fourth, we cannot rule out the possibility of cross-reactivity between the MR agonist and antagonist with GR. Although fludrocortisone is known to exert some glucocorticoid activity, its affinity for MR is 15 -fold higher than that for GR (Agarwal et al. 1977). There have been no reports that we know of regarding the interaction of canrenoic acid with GR at any dose. Fifth, when we did not see an effect of a manipulation on basal steroid production, we cannot conclude with certainty that there is none as an equally plausible interpretation would be that our assay systems are not sensitive enough to pick up small effects. Finally, extrapolation of these rat studies to humans is uncertain.

In conclusion, in addition to the classical, long feedback loops regulating adrenal steroid production, the present study supports the hypothesis that there are negative ultra-short regulatory loops mediated specifically by MR on aldosterone secretion and GR on corticosterone production in isolated ZG and ZF/ZR cells, respectively. We report here the unexpected finding that $M R$ activation also negatively regulates glucocorticoid secretion in ZF/ZR cells. How these short feedback loops interact with their long feedback loops is uncertain. However, these findings raise intriguing questions regarding the physiologic regulation and potential pathophysiologic dysregulation of the production of these steroids.

\section{Declaration of interest}

The authors declare that there is no conflict of interest that could be perceived as prejudicing the impartiality of the research reported.

\section{Funding}

This work was supported by the National Institute of Health National Heart, Lung and Blood Institute Grants R01HL11476 (G H W), R01HL104032 ( $L \mathrm{H}$ P), R01HL096518 ( $\mathrm{R}$ R), the American Heart Association: 14GRNT20500000 (L H P) and by fellowships from the Ministry of Rural and Regional Development Malaysia (MARA) (C C).

\section{Acknowledgements}

The authors thank Paul Loutraris for his expert assistance with the animal protocols and preparing all experimental materials.

\section{References}

Agarwal MK, Coupry F \& Philippe M 1977 Physiological activity and receptor binding of 9 alpha fluorohydrocortisone. Biochemical and Biophysical Research Communications 78 747-753. (doi:10.1016/0006291X(77)90242-X)

Aguilera G \& Catt KJ 1979 Loci of action of regulators of aldosterone biosynthesis in isolated glomerulosa cells. Endocrinology 104 1046-1052. (doi:10.1210/endo-104-4-1046)
() 2017 Society for Endocrinology Printed in Great Britain
Published by Bioscientifica Ltd 
Arvat E, Maccagno B, Giordano R, Pellegrino M, Broglio F, Gianotti L, Maccario M, Camanni F \& Ghigo E 2001 Mineralocorticoid receptor blockade by canrenoate increases both spontaneous and stimulated adrenal function in humans. Journal of Clinical Endocrinology \& Metabolism 86 3176-3181. (doi:10.1210/jc.86.7.3176)

Asser L, Hescot S, Viengchareun S, Delemer B, Trabado S \& Lombes M 2014 Autocrine positive regulatory feedback of glucocorticoid secretion: glucocorticoid receptor directly impacts H295R human adrenocortical cell function. Molecular and Cellular Endocrinology 395 1-9. (doi:10.1016/j.mce.2014.07.012)

Baird A, Kan KW \& Solomon S 1983 Androstenedione-mediated inhibition of 11 beta-hydroxylation in monolayer cell cultures of fetal calf adrenals. Journal of Steroid Biochemistry 18 581-584. (doi:10.1016/0022-4731(83)90134-6)

Birmingham MK \& Kurlents E 1958 Inactivation of ACTH by isolated rat adrenals and inhibition of corticoid formation by adrenocortical hormones. Endocrinology 62 47-60. (doi:10.1210/endo-62-1-47)

Black WE, Crampton RS, Verdesca AS, Nedeljkovic RI \& Hilton JG 1961 Inhibitory effect of hydrocortisone and analogues on adrenocortical secretion in dogs. American Journal of Physiology 201 1057-1060.

Boulkroun S, Samson-Couterie B, Dzib JF, Lefebvre H, Louiset E, Amar L, Plouin PF, Lalli E, Jeunemaitre X, Benecke A, et al. 2010 Adrenal cortex remodeling and functional zona glomerulosa hyperplasia in primary aldosteronism. Hypertension 56 885-892. (doi:10.1161/ HYPERTENSIONAHA.110.158543)

Braley LM \& Williams GH 1977 Rat adrenal cell sensitivity to angiotensin II, alpha-1-24-ACTH, and potassium: a comparative study. American Journal of Physiology 233 E402.

Briet M \& Schriffin EL 2010 Aldosterone: effects on the kidney and cardiovascular system. Nature Reviews Nephrology 6 261-273. (doi:10.1038/nrneph.2010.30)

Buckley TM, Mullen BC \& Schatzberg AF 2007 The acute effects of a mineralocorticoid receptor (MR) agonist on nocturnal hypothalamic-adrenal-pituitary (HPA) axis activity in healthy controls. Psychoneuroendocrinology 32 859-864. (doi:10.1016/j. psyneuen.2007.05.016)

Burton TJ, Azizan EA \& Brown MJ 2011 Investigating the function of an aldosterone response pathway in primary human adrenocortical cells obtained from Conn's and phaeochromocytoma patients. European Journal of Pharmacology 657 184-189. (doi:10.1016/j.ejphar.2011.01.051)

Carsia RV \& Malamed S 1983 Glucocorticoid control of steroidogenesis in isolated rat adrenocortical cells. Biochimica et Biophysica Acta 763 83-89. (doi:10.1016/0167-4889(83)90028-9)

Clapham JC \& Turner NC 1997 Effects of the glucocorticoid II receptor antagonist mifepristone on hypertension in the obese Zucker rat. Journal of Pharmacology and Experimental Therapeutics 282 1503-1508.

Connell JMC \& Davies E 2005 The new biology of aldosterone. Journal of Endocrinology 186 1-20. (doi:10.1677/joe.1.06017)

Darbeida H \& Durand P 1987 Glucocorticoid enhancement of adrenocorticotropin-induced 3',5'-cyclic adenosine monophosphate production by cultured ovine adrenocortical cells. Endocrinology 121 1051-1055. (doi:10.1210/endo-121-3-1051)

Eisenstein AB \& Strack I 1961 Effect of sodium deficiency on secretion of hormones by the adrenal cortex. Endocrinology 68 121-124. (doi:10.1210/endo-68-1-121)

Giroud CJP, Stachenko J \& Venning EH 1956 Secretion of aldosterone by the zona glomerulosa of rat adrenal glands incubated in vitro. Experimental Biology and Medicine 92 154-158. (doi:10.3181/00379727-92-22416)

Herman JP, Patel PD, Akil H \& Watson SJ 1989 Localization and regulation of glucocorticoid and mineralocorticoid receptor messenger RNAs in the hippocampal formation of the rat. Molecular Endocrinology 3 1886-1894. (doi:10.1210/mend-3-11-1886)
Hill CD \& Singer B 1968 Inhibition of the response to pituitary adrenocorticotrophic hormone in the hypophysectomized rat by circulatory corticosterone. Journal of Endocrinology 42 301-309. (doi:10.1677/joe.0.0420301)

Latner AL, Cook DB \& Solanki KU 1977 Inhibition of binding of corticotropin-(1-24)-tetracosapeptide (Synacthen) to membrane receptors of adrenal cortex by cortisol. Biochemical Journal 164 477-480. (doi:10.1042/bj1640477)

Lembke A, Gomez R, Tenakoon L, Keller J, Cohen G, Williams GH, Kraemer FB \& Schatzberg AF 2013 The mineralocorticoid receptor agonist, fludrocortisone, differentially inhibits pituitary-adrenal activity in humans with psychotic major depression. Psychoneuroendocrinology 38 115-121. (doi:10.1016/j.psyneuen.2012.05.006)

Lesouhaitier O, Chiappe A \& Rossier MF 2001 Aldosterone increases T-type calcium currents in human adrenocarcinoma (H295R) cells by inducing channel expression. Endocrinology $1424320-4330$. (doi:10.1210/endo.142.10.8435)

Li L, Wu Z, Yang X, Ni Y, Parvizi N \& Zhao R 2011 Effect of glucocorticoids pretreatment on steroidogenic capacity of adrenocortical cells isolated from Meishan piglets. In Vitro Cellular and Developmental Biology Animal 47 425-430. (doi:10.1007/s11626-011-9421-8)

Lombes M, Alfaidy N, Eugene E, Lessana A, Farman N \& Bonvalet JP 1995 Prerequisite for cardiac aldosterone action. Mineralocorticoid receptor and 11 beta-hydroxysteroid dehydrogenase in the human heart. Circulation 92 175-182. (doi:10.1161/01.CIR.92.2.175)

Marusic ET \& Mulrow PJ 1967 Stimulation of aldosterone biosynthesis in adrenal mitochondria by sodium depletion. Journal of Clinical Investigation 46 2101-2108. (doi:10.1172/JCI105697)

Mornet E, Dupont J, Vitek A \& White PC 1989 Characterization of two genes encoding human steroid 11 beta-hydroxylase (P-450(11) beta) Journal of Biological Chemistry 265 20961-20967.

Morrow LB, Burrow GN \& Mulrow PJ 1967 Inhibition of adrenal protein synthesis by steroids in vitro. Endocrinology 80 883-888. (doi:10.1210/ endo-80-5-883)

Otte C, Yassouridis A, Jahn H, Maass P, Stober N, Wiedemann K \& Kellner M 2003 Mineralocorticoid receptor-mediated inhibition of the hypothalamic-pituitary-adrenal axis in aged humans. Journals of Gerontology Series A: Biological Sciences and Medical Sciences $\mathbf{5 8}$ B900-B905. (doi:10.1093/gerona/58.10.B900)

Pearce P \& Funder JW 1987 High affinity aldosterone binding sites (type I receptors) in rat heart. Clinical and Experimental Pharmacology and Physiology 14 859-866. (doi:10.1111/j.1440-1681.1987.tb02422.x)

Peron FG, Moncloa F \& Dorfman RI 1960 Studies on the possible inhibitory effect of corticosterone on corticosteroidogenesis at the adrenal level in the rat. Endocrinology 67 379-388. (doi:10.1210/endo67-3-379)

Quinn SJ, Enyedi P, Tillotson DL \& Williams GH 1991 Kinetics of cytosolic calcium and aldosterone responses in rat adrenal glomerulosa cells. Endocrinology 129 2431-2441. (doi:10.1210/endo129-5-2431)

Saito E, Ichikawa Y \& Homma M 1979a Direct inhibitory effect of dexamethasone on steroidogenesis of human adrenal in vivo. Journal of Clinical Endocrinology \& Metabolism 48 861-863. (doi:10.1210/jcem48-5-861)

Saito E, Mukai M, Muraki T, Ichikawa Y \& Homma M 1979b Inhibitory effects of corticosterone on cell proliferation and steroidogenesis in the mouse adrenal tumor cell line Y-1. Endocrinology 104 487-492. (doi:10.1210/endo-104-2-487)

Wellhoener P, Born J, Fehm HL \& Dodt C 2004 Elevated resting and exercise-induced cortisol levels after mineralocorticoid receptor blockade with canrenoate in healthy humans. Journal of Clinical Endocrinology \& Metabolism 89 5048-5052. (doi:10.1210/jc.2004-0086)

Received in final form 23 December 2016

Accepted 17 January 2017

Accepted Preprint published online 17 January 2017 http://joe.endocrinology-journals.org

DOI: 10.1530/JOE-16-0452
(C) 2017 Society for Endocrinology Printed in Great Britain 